\title{
A National Study of Out-of-Pocket Expenditures for Mammography Screening
}

\author{
Traci LeMasters, M.A., and Usha Sambamoorthi, Ph.D.1,2
}

\begin{abstract}
Objectives: To identify variations in screening mammography expenditures, primarily out-of-pocket and total expenditures, of women 40-64 years of age in the United States and factors associated with variations.

Methods: Retrospective analysis of data collected from the 2007 and 2008 Medical Expenditure Panel Survey (MEPS). The sample included 2020 women 40-64 years of age who received one mammogram in 2007 or 2008. Ordinary least squares regression was used to describe relationships among out-of-pocket mammography expenditures, total mammography expenditures, and out-of-pocket mammography expenditures as a percentage of total mammography expenditures and such independent variables as insurance status and type, income, region of the United States, and type of facility where a mammogram was received.

Results: The average out-of-pocket expenditure for a mammogram in 2007 or 2008 was \$33, representing 14.1\% of the total mammogram expenditure (\$266). After controlling for demographic and health factors, women who were uninsured, were from the Midwest, and had a mammogram at an office-based facility had greater out-ofpocket mammography expenditures. Women who were uninsured, lived in the South, and received their mammogram at an office-based facility had out-of-pocket mammography expenditures that represented a greater proportion of the total mammography expenditures.

Conclusions: Large variations in out-of-pocket expenditures were observed among women with and without insurance and between insurance types, geographic regions of the United States, and types of facilities where mammograms were received. A higher financial burden of mammography screening among some subgroups of women may act as a barrier to future mammography screening.
\end{abstract}

\section{Introduction}

I N THE United States, breast cancer is the second leading cause of cancer-related deaths and the most frequently diagnosed type of cancer. ${ }^{1}$ It was estimated that there would be 207,090 new cases and 39,840 deaths attributed to breast cancer in $2010 .^{2}$ Breast cancer screening, especially mammography, has been shown to be important for detecting cancer at an early stage when it is asymptomatic, thereby decreasing mortality. ${ }^{3-5}$ Although the Healthy People 2010 objective of screening $70 \%$ of women eligible for mammography had been achieved as of 1999, many women still do not receive recommended mammography screening. ${ }^{6-9}$ In fact, mammography rates have been on the decline since 2005 and were at $67 \%$ in 2008 . $^{9}$

An important barrier to receiving a mammogram is the woman's or the family's absolute out-of-pocket expenditure for the service. ${ }^{6,10}$ Underuse of mammography screening because of burdensome out-of-pocket expenditures may be most common among women who are of low income, ${ }^{6,8,11-13}$ are uninsured, ${ }^{6,7,12-14}$ are insured through health plans with increased cost sharing, ${ }^{15-19}$ or overestimate their copayment. ${ }^{6,10}$ In fact, both the perceived and actual out-of-pocket expenditures have been demonstrated to be the most important aspect of cost that acts as a barrier to receiving a mammogram. ${ }^{6,10}$ There is some evidence that among some groups of women, an out-of-pocket expenditure $>\$ 10$ can significantly decrease appropriate mammography use. ${ }^{16}$

Variations in out-of-pocket expenditures are known to occur between different types of insurance. Women who are uninsured or insured through private plans are more likely to pay some or all of the mammography charge compared to women insured through Medicare or Medicaid. ${ }^{7}$ Variations in charges for mammograms by different types of facilities can also lead to variations in out-of-pocket mammography expenditures. ${ }^{20}$ For example, outpatient hospital facilities that have separate facility and provider charges may have an overall higher total charge

\footnotetext{
${ }^{1}$ School of Pharmacy, Department of Pharmaceutical Systems and Policy, West Virginia University, Morgantown, West Virginia.

${ }^{2}$ Department of Community Health and Preventive Medicine, Morehouse School of Medicine, Atlanta, Georgia.
} 
for the same mammogram that can be received in an officebased facility. Previous studies have also recognized that women who live in different geographic regions of the United States or metro status experience variations in the out-of-pocket expenditure they pay for a mammogram., 70,21

Previous studies have highlighted the impact of women's outof-pocket expenditures, or perceived out-of-pocket expenditures, on their decision to be screened and how sensitive the decision is to changes in out-of-pocket expenditures. ${ }^{6,10,15-17}$ Furthermore, it is not reporting having had a mammogram within a specified period that is important but rather the continuation of mammography screening that is crucial to improved breast cancer detection. ${ }^{1,22-27}$ However, a high out-of-pocket expenditure for a single mammogram may influence a woman's decision to seek further mammography screening and her decision to receive other recommended preventive health screenings. ${ }^{28-30}$

The primary objective of this study was to estimate and examine subgroup variations in out-of-pocket mammography expenditures. We examined variations in out-of-pocket expenditures for women who reported receiving one mammogram in the year 2007 or 2008. The variations in out-ofpocket expenditures by insurance, income, region, and site of mammogram were analyzed within the health services use conceptual framework proposed by Andersen. The Andersen model posits that health services use and health outcomes of an individual are influenced by his or her environment, predisposing characteristics, and enabling, need, and health behaviors. ${ }^{31,32}$ Prior research has used Andersen's model to examine factors that affect out-of-pocket expenditures in multivariate analysis. ${ }^{33}$ For the purposes of current research, we focused only on specific enabling (presence and type of insurance and income) and healthcare environment factors (facility type and geographic region) while controlling for predisposing, need, and health behaviors. Healthcare environment associations with out-of-pocket mammography expenditures were determined by the region of the United States in which a woman resided and the type of facility in which the mammogram was received. Regions are divided into Medical Expenditure Panel Survey (MEPS) as the Northeast, Midwest, South, and West. ${ }^{34}$ Given that outpatient facilities apply separate charges for the physician and the facility compared to office-based facilities that apply only a physician's charge, out-of-pocket mammography expenditures were compared for two types of facilities in which a mammogram could be received. These facilities were either an office-based or a clinic setting and an outpatient department within a hospital.

\section{Materials and Methods}

Data

The data for this study are from the 2007 and 2008 MEPS. ${ }^{35}$ As per the recommendation from the MEPS, we pooled 2 years of data to gain enough sample size and to derive reliable estimates. ${ }^{36}$ MEPS collects data in an overlapping panel survey of United States noninstitutionalized civilians. The households selected for each panel of the MEPS were a subsample of households participating in the previous year's National Health Interview Survey (NHIS). The NHIS oversamples blacks, Hispanics, and starting in 2006, Asians. MEPS oversamples additional policy-relevant subgroups, such as low-income households. ${ }^{34}$ The survey data was collected in five rounds over a 2 1/2-year calendar period from individuals, families, their medical providers, and employers in the United States on information pertaining to the use, cost, and payment of health services as well as information on demographics, employment, health status, and satisfaction with services received. ${ }^{37}$

Specific files used in this study were the Full Year Consolidated Data File from the Household Component Full Year File and the Outpatient Visits File and Office-Based Medical Provider Visits File from Household Component Event Files. Demographics and other individual-level information were derived from the Household Component File. The expenditures data were derived from both the Households and the Medical Provider Component Files. Households reported on expenditures for nonphysician visits, dental and vision services, other medical equipment and services, and home healthcare not provided by an agency, and data on expenditures for care provided by home health agencies, office-based visits to physicians, hospital-based events, and prescribed medicines were collected from medical providers. In the MEPS, expenditures refer to payments for healthcare services from about 13 sources, including (1) out-of-pocket by the patient or the patient's family, (2) Medicare, (3) Medicaid, (4) private insurance, (5) Veterans' Administration, excluding CHAMPVA (Civilian Health and Medical Program of the Department of Veterans Affairs), (6) TRICARE (a health care program offered by the Military Health System for active duty service members, National Guard and Reserve members, their families, survivors, and certain former spouses), (7) other federal sources, (8) other state and local sources, (9) Workers' Compensation, and (10) other unclassified sources. The response rate for the 2007 and 2008 MEPS was $56.9 \%$ and $59.3 \%$, respectively. ${ }^{38}$ Data pertaining to individual characteristics and healthcare expenditures were collected from the individual responder. Missing data on expenditures was imputed using a weighted sequential hot-deck procedure for most medical visits and services. In general, this procedure imputes data from events with complete information to events with missing information but similar characteristics. ${ }^{39}$

\section{Study sample}

The 2007 MEPS surveyed 30,964 individuals, making up 11,615 families. ${ }^{34}$ The 2008 MEPS surveyed 33,066 individuals, making up 12,316 families. ${ }^{40}$ Our sample $(n=2,020)$ of women 40-64 years of age who reported having at least, but no more than, one mammogram in the 2007 or 2008 calendar year and alive was selected based on receipt of mammograms using the Office-Based Medical Provider Visits File and the Outpatient Visits File. Our sample excluded women who received more than one mammogram during these years because their mammograms may have been for diagnostic or surveillance purposes. Additionally, women were excluded if they received no mammogram or if the response to having had a mammogram was missing. Missing responses to all other questions were grouped into the missing response category. Therefore, 298 women were excluded because they had more than one mammogram and 430 were excluded because of a missing response about receipt of mammogram.

\section{Measures}

Dependent variable: Mammography expenditures. Total mammography expenditures were measured as the total of payments received by the insurance provider and out-of- 
pocket expenditures by self or family. Insurance provider payments consisted of private insurance, Medicaid, Medicare, other public insurance, and any other third-party source of payment. The out-of-pocket mammography expenditures may be in the form of either copayment for individuals with insurance or direct payment for the uninsured. Mammography expenditures were derived from both the Office-Based Medical Provider Visits File and the Outpatient Visits File based on the recorded type of services. We calculated mammography expenditures, using the indicator, whether or not the patient had a mammogram during the visit. Office-based includes expenses for visits to both physician and nonphysician medical providers seen in the office setting. Hospital outpatient includes expenses for visits to both physicians and other medical providers seen in hospital outpatient departments, including payments for services covered under the basic facility charge and those for separately billed physician services. (www.meps.ahrq.gov/mepsweb/data_files/ publications/st203/stat203.pdf). ${ }^{41}$

The primary dependent variables of interest in this study were the woman's and family's out-of-pocket expenditures for a mammogram and out-of-pocket mammography expenditures as a percent of the total mammography expenditures. Also of interest were the total mammography expenditures by all payers. Because of changes in medical care costs from year to year, we expressed all expenditures in 2008 dollars using the consumer price index for medical care services (www.bls.gov/ cpi/cpid08av.pdf). ${ }^{42}$

Based on our conceptual framework, variables in the predisposing group were age, race (white, African American, and other), and ethnicity (Latina). The enabling group examined the effects of marital status (married or not married), education (less than high school and high school and above), poverty (poor and not poor), employment status (employed or not employed), insurance status (insured or uninsured), type of insurance (Medicare, Medicaid, private, and other), and having a usual source of care (yes or no) on out-of-pocket mammography expenditures. The association between need and out-of-pocket mammography expenditures was determined by analyzing variation between states of perceived mental and physical health (excellent/very good, good, fair/ poor) and by the presence or absence of common disease states, including arthritis, diabetes, heart disease, hypertension, and stroke. A report of receiving a general and dental checkup, Papanicolau test, and influenza immunization within the past year, along with body mass index (BMI), cigarette smoking status (yes or no), and physical activity (yes or no), where included as measures of personal health practices. Clinical preventive services were combined into two groups by count: (1) received one or two services and (2) received three or four services. We also used year of observation (2007 vs. 2008) to control for changes in medical care over time.

\section{Statistical techniques}

Analysis was performed for women 40-64 years of age. Group differences were tested for statistical difference using $t$ tests and $F$ tests. Ordinary least squares regression was used to estimate the relationship between independent variables and mammography expenditures. Parameter estimates were considered significant if their $p$ values were $<0.001$. Reference groups were set at being white, aged 60-64, not married, completing high school or above high school, not poor, having private insurance, having fair/poor perceived mental or physical health, nonmetro status, living in the West region, and receiving a mammogram in an office-based facility. Chronic conditions were compared by presence or absence, and clinical preventive services were compared according to their count. Log transformation was performed on regression estimates because many women had zero out-of-pocket mammography expenditures. Results from logged expenditures models generally were consistent and are not reported in this article. All statistical calculations were performed using survey procedures in SAS version 9.2 software (SAS Institute Inc., Cary, NC), which accounted for the complex sample design.

\section{Results}

Table 1 provides a description of the women aged between 40 and 64 from the 2007 and 2008 MEPS who received one mammogram in 2007 or 2008. Among this group, 1331 of the 2020 women were white. After weighting, $80 \%$ of the women with one mammogram in 2007 and 2008 were white. The majority of the sample were not poor $(85.1 \%)$, had private insurance $(86.8 \%)$, and were distributed throughout the different geographic regions of the United States (Northeast $20.2 \%$, Midwest 25.9\%, South 34.4\%, and West 19.5\%), and about two thirds (65.1\%) of women received their mammogram at an office-based facility.

The average out-of-pocket mammography expenditure for all groups in 2007 was $\$ 32.90$, and the average total mammography expenditure from all payers was $\$ 266.49$. Women's out-of-pocket mammography expenditures were on the average about $14 \%$ of the total mammography expenditures.

\section{Out-of-pocket mammography expenditures}

Statistically significant differences in out-of-pocket mammography expenditures were observed between women who were insured (\$31.32) or uninsured (\$60.03) (Table 2). Insured women with the lowest out-of-pocket mammography expenditures were those with Medicaid coverage (\$3.60). Among women with insurance, the greatest out-of-pocket mammography expenditures were for women who were privately insured (\$33.04), yet women without any insurance had the greatest out-of-pocket mammography expenditures of all groups (\$60.03). Women who were classified as not poor had higher out-of-pocket mammography expenditures (\$34.27) than women who were poor (\$25.10). White women had the highest out-of-pocket mammography expenditures (\$35.48) compared to African Americans (\$21.26), Latinas (\$28.72), and women classified as another race (\$16.61). Women residing in the Midwest region of the United States had the highest out-of-pocket mammography expenditures (\$46.76) of all regions, and those residing in the Northeast and West had the lowest (\$23.95 and \$24.61). Women who received a mammogram at an office-based facility (\$35.29) had higher out-of-pocket mammography expenditures than women who received their mammogram at an outpatient facility (\$28.45).

Findings from regression models (Table 3) showed that uninsured women had greater out-of-pocket mammography expenditures than women with private insurance. Women insured through Medicare and Medicaid paid less out-ofpocket compared to those with private insurance. When compared to women who were not poor, those who were 
TABle 1. Description of Women With Mammogram: Medical Expenditure Panel Survey, 2007-2008

\begin{tabular}{|c|c|c|c|c|c|}
\hline \multirow{2}{*}{\multicolumn{3}{|c|}{$\begin{array}{l}\text { 1 ABLE 1. DESCRIPTION OF WOMEN WITH MAMMOGRAM: } \\
\text { MEDICAL EXPENDITURE PANEL SURVEY, 2007-2008 }\end{array}$}} & \multicolumn{3}{|c|}{ TABLE 1. (CONTINUED) } \\
\hline & & & & $\mathrm{n}$ & $W t \%$ \\
\hline \multirow[b]{2}{*}{ All } & \multirow{2}{*}{$\begin{array}{c}\mathrm{n} \\
2020^{\mathrm{a}}\end{array}$} & \multirow{2}{*}{$\begin{array}{l}\text { Wt \% } \\
100.0\end{array}$} & All & $2020^{\mathrm{a}}$ & 100.0 \\
\hline & & & \multicolumn{3}{|l|}{ Region } \\
\hline \multicolumn{3}{|l|}{ Race/ethnicity } & Northeast & 347 & 20.2 \\
\hline White & 1331 & 79.7 & Midwest & 504 & 25.9 \\
\hline African American & 262 & 7.9 & South & 705 & 34.4 \\
\hline Latina & 290 & 7.2 & West & 464 & 19.5 \\
\hline Other & 137 & 5.1 & Mammogran & & \\
\hline \multicolumn{3}{|l|}{ Age, years } & OTP & 687 & 34.9 \\
\hline $40-50$ & 756 & 36.4 & Office & 1333 & 65.1 \\
\hline $50-59$ & 870 & 42.5 & Year & & \\
\hline $60-64$ & 394 & 21.1 & 2007 & 993 & 49.2 \\
\hline \multicolumn{3}{|l|}{ Marital status } & 2008 & 1027 & 50.8 \\
\hline Married & 1378 & 69.5 & & & \\
\hline Not married & 642 & 30.5 & \multirow{7}{*}{\multicolumn{3}{|c|}{$\begin{array}{l}\text { Based on women aged } 40-64 \text {, alive at the end of the year, who } \\
\text { received one mammogram in } 2007 \text { or in } 2008 \text {. } \\
\text { aFor some variables, numbers do not add to } 2020 \text { due to missing } \\
\text { data (e.g., education, usual source of care). } \\
\text { Wt \%, weighted \%, OTP, out-patient hospital; TRICARE, a health } \\
\text { care program offered by the Military Health System for active duty } \\
\text { service members, National Guard and Reserve members, their } \\
\text { families, survivors, and certain former spouses. }\end{array}$}} \\
\hline \multicolumn{3}{|l|}{ Education } & & & \\
\hline Less than high school & 254 & 12.6 & & & \\
\hline High school and above & 1762 & 87.2 & & & \\
\hline Poverty status & & & & & \\
\hline Poor & 409 & 14.9 & & & \\
\hline Not poor & 1611 & 85.1 & & & \\
\hline \multicolumn{6}{|c|}{ (1) } \\
\hline Yes & 163 & 5.5 & & & \\
\hline No & 1857 & 94.5 & & & \\
\hline \multicolumn{3}{|l|}{ Medicare } & \multirow{4}{*}{\multicolumn{3}{|c|}{$\begin{array}{l}\text { poor had lower out-of-pocket mammography expenditures. } \\
\text { Women residing in the Midwest }(\$ 24.97) \text { and South }(\$ 9.45) \\
\text { regions of the United States had greater out-of-pocket mam- } \\
\text { mography expenditures compared to women residing in the }\end{array}$}} \\
\hline Yes & 93 & 3.9 & & & \\
\hline No & 1927 & 96.1 & & & \\
\hline \multicolumn{3}{|l|}{ Medicaid } & & & \\
\hline Yes & 152 & 5.1 & West, where & neast re & out-of- \\
\hline No & 1868 & 94.9 & pocket mam & that we & lower \\
\hline \multicolumn{3}{|l|}{ Private insurance } & $(-\$ 0.76) \mathrm{com}$ & st. Wom & ceive a \\
\hline Yes & 1653 & 86.8 & mammogran & t facilit & er out- \\
\hline No & 367 & 13.2 & of-pocket m & ures the & n who \\
\hline \multicolumn{3}{|l|}{ TRICARE } & \multirow{6}{*}{\multicolumn{3}{|c|}{$\begin{array}{l}\text { received a mammogram at an office-based facility. As com- } \\
\text { pared to white women, African Americans, Latinas, and } \\
\text { mamen who are of another race had lower out-of-pocket } \\
\text { mamography expenditures. }\end{array}$}} \\
\hline Yes & 62 & 3.1 & & & \\
\hline No & 1958 & 96.9 & & & \\
\hline \multicolumn{3}{|l|}{ Usual source of care } & & & \\
\hline Yes & 1863 & 92.9 & & & \\
\hline No & 156 & 7.1 & & & \\
\hline \multicolumn{3}{|l|}{ Perceived health } & \multirow{3}{*}{\multicolumn{3}{|c|}{$\begin{array}{l}\text { Out-of-pocket mammography expenditures as percent } \\
\text { of total mammography expenditures }\end{array}$}} \\
\hline Excellent/very good & 1164 & 63.0 & & & \\
\hline Good & 586 & 26.8 & & & \\
\hline
\end{tabular}

Fair/poor 270

Mental health

$\begin{array}{lrr}\text { Excellent/very good } & 1343 & 70.2 \\ \text { Good } & 534 & 24.0\end{array}$

Fair/poor 143

Exercise

Three times a week $\quad 1149 \quad 59.3$

No exercise 868

Body mass index

Under/normal 709

Overweight 589

Obese 644

Missing 78

Current smoker

Current smoker 258

Other 1661

missing 101

Metro status

Metro

1708

Nonmetro

TAble 1. (Continued)

Based on women aged 40-64, alive at the end of the year, who

${ }^{\text {a}}$ For some variables, numbers do not add to 2020 due to missing ata (e.g., education, usual source of care). service members, National Guard and Reserve members, their families, survivors, and certain former spouses.

26.8

10.3

Among uninsured women, out-of-pocket mammography expenditures represented $31.0 \%$ of the total mammography expenditures (Table 2). Out-of-pocket mammography expenditures among women insured through Medicaid were $3.6 \%$ of the total mammography expenditures, as compared to women with private insurance who paid $13.7 \%$ of the total mammography expenditures. Among race/ethnicity groups, Latina women paid the highest proportion (18.0\%) of total mammography expenditures, with white women paying $14.2 \%$ out-of-pocket. Women residing in the South region of the United States paid the highest percentage of the total mammography expenditures $(16.5 \%)$, whereas those residing in the Northeast only paid $10.0 \%$. Women who received a mammogram at an office-based facility paid a higher percentage of the total mammography expenditures $(16.0 \%)$ compared to woman who received a mammogram from an outpatient facility (10.4\%) (Table 2).

83.9

16.1

\section{Total mammography expenditures}

Women who were uninsured had significantly lower total mammography expenditures (\$170.47) compared to those who 
Table 2. Out-of-Pocket and Mammogram Expenditures (2008 dollars): Women Aged 40-64 with One Mammogram: Medical Expenditure Panel Survey, 2007-2008

\begin{tabular}{|c|c|c|c|c|c|c|}
\hline & \multicolumn{2}{|c|}{ Out-of-pocket expenditures } & \multicolumn{2}{|c|}{ Mammogram expenditures } & \multicolumn{2}{|c|}{$\%$ OOP to mammogram expenditures } \\
\hline & Mean & $S E$ & Mean & $S E$ & Mean & $S E$ \\
\hline All & 32.90 & 2.32 & 266.49 & 10.09 & 14.08 & 0.67 \\
\hline \multicolumn{7}{|l|}{ Race/ethnicity } \\
\hline White & 35.48 & 2.81 & 268.43 & 11.44 & 14.24 & 0.81 \\
\hline African American & 21.26 & 5.40 & 236.59 & 19.48 & 11.40 & 2.12 \\
\hline Latina & 28.72 & 4.38 & 228.07 & 27.82 & 17.96 & 1.64 \\
\hline Other & 16.61 & 3.36 & 336.82 & 76.46 & 10.26 & 1.53 \\
\hline \multicolumn{7}{|l|}{ Age, years } \\
\hline $40-50$ & 35.39 & 3.85 & 287.68 & 20.99 & 13.80 & 1.02 \\
\hline $50-59$ & 34.06 & 3.89 & 264.32 & 14.75 & 15.17 & 1.02 \\
\hline $60-64$ & 26.26 & 4.22 & 234.25 & 15.71 & 12.35 & 1.57 \\
\hline \multicolumn{7}{|l|}{ Poverty status } \\
\hline Poor & 25.10 & 3.82 & 209.98 & 12.87 & 13.76 & 1.41 \\
\hline Not Poor & 34.27 & 2.68 & 276.40 & 11.67 & 14.13 & 0.72 \\
\hline \multicolumn{7}{|l|}{ Uninsured } \\
\hline Yes & 60.03 & 12.91 & 170.47 & 18.90 & 30.96 & 3.74 \\
\hline No & 31.32 & 2.33 & 272.09 & 10.67 & 13.09 & 0.66 \\
\hline \multicolumn{7}{|l|}{ Medicare } \\
\hline Yes & 8.68 & 2.48 & 175.22 & 22.81 & 6.14 & 1.69 \\
\hline No & 33.88 & 2.40 & 270.20 & 10.49 & 14.40 & 0.69 \\
\hline \multicolumn{7}{|l|}{ Medicaid } \\
\hline Yes & 3.60 & 1.53 & 192.42 & 25.08 & 3.55 & 1.28 \\
\hline No & 34.47 & 2.48 & 270.47 & 10.28 & 14.65 & 0.71 \\
\hline \multicolumn{7}{|l|}{ Private insurance } \\
\hline Yes & 33.04 & 2.53 & 280.29 & 11.46 & 13.69 & 0.71 \\
\hline No & 31.94 & 5.97 & 175.38 & 11.59 & 16.62 & 2.08 \\
\hline \multicolumn{7}{|l|}{ TRICARE } \\
\hline Yes & 21.02 & 3.09 & 222.41 & 36.56 & 8.76 & 1.29 \\
\hline No & 33.28 & 2.39 & 267.89 & 10.12 & 14.25 & 0.69 \\
\hline \multicolumn{7}{|l|}{ Region } \\
\hline Northeast & 23.95 & 3.45 & 303.06 & 29.82 & 9.99 & 1.47 \\
\hline Midwest & 46.76 & 7.46 & 295.61 & 17.90 & 14.56 & 1.15 \\
\hline South & 32.44 & 2.75 & 228.72 & 14.14 & 16.52 & 1.27 \\
\hline West & 24.61 & 4.49 & 256.58 & 24.82 & 13.37 & 1.48 \\
\hline \multicolumn{7}{|l|}{ Mammogram site } \\
\hline Outpatient hospital & 28.45 & 3.27 & 309.52 & 17.98 & 10.43 & 0.93 \\
\hline Office-based & 35.29 & 3.04 & 243.39 & 12.49 & 16.04 & 0.86 \\
\hline
\end{tabular}

Based on 2020 women aged group 40-64 years with one mammogram in 2007 or 2008. Significant group differences in out-of-pocket and mammogram expenditures were tested with $F$ tests and $t$ tests. All group differences were significant at $p<0.001$ based on $t$ tests or $F$ tests. Out-of-pocket spending on mammograms to total expenditures is expressed in terms of percentages.

OOP, Out-of-pocket expenditures; SE, standard error.

had insurance (\$272.09). Women insured by Medicare (\$175.22) and Medicaid (\$192.42) had lower total mammography expenditures compared to women with private insurance (\$280.29). Women who were poor had lower total mammography expenditures (\$209.98) compared to those who are not poor $(\$ 276.40)$. Women classified as another race had the highest total mammography expenditures (\$336.82) compared to whites (\$268.43), African Americans (\$236.59), and Latinas (\$228.07). Between office-based and outpatient facilities, women who received a mammogram at an outpatient facility had a total mammography expenditures $>\$ 70$ more than women who received a mammogram at an office-based facility (Table 2).

Findings from our regression on mammography expenditures summarized in Table 3 suggest that women who were insured by Medicare, Medicaid, and other insurances had lower total mammography expenditures compared to women with private insurance. Women who were uninsured had total mammography expenditures that were lower than those of women with private insurance. When compared to women who were not poor, those who were poor had lower total mammography expenditures. Women residing in the Northeast and Midwest had total mammography expenditures that were higher than those in the West, and those in the South were lower. Furthermore, women who received their mammogram at an outpatient hospital facility had greater total mammography expenditures than those from an office-based facility. Women of another race and Latinas had greater total mammography expenditures than white women, whereas African Americans had lower total mammography expenditures (Table 3.).

\section{Discussion}

To our knowledge, this is the first study using a nationally representative survey sample to estimate women's average 
Table 3. Ordinary Least Souares Regression on Out-of-Pocket and Mammogram Expenditures (2008 dollars): Women Aged 40-64 Years with One Mammogram: Medical Expenditure Panel Survey, 2007-2008

\begin{tabular}{|c|c|c|c|c|c|c|}
\hline & \multicolumn{2}{|c|}{ Out-of-pocket expenditures } & \multicolumn{2}{|c|}{ Mammogram expenditures } & \multicolumn{2}{|c|}{$\%$ OOP to mammogram expenditures } \\
\hline & Beta & $S E$ & Beta & $S E$ & Beta & $S E$ \\
\hline \multicolumn{7}{|l|}{ Race/ethnicity } \\
\hline African American & -16.534 & $0.129^{* * *}$ & -12.677 & $0.661^{* * *}$ & -3.710 & $0.065^{* * *}$ \\
\hline Latina & -4.976 & $0.126^{* * *}$ & 0.143 & 1.575 & 3.180 & $0.061^{* * *}$ \\
\hline Other & -14.217 & $0.526^{* * *}$ & 74.414 & $3.863^{* * *}$ & -2.913 & $0.261^{* * *}$ \\
\hline White (ref) & 0.000 & 0.000 & 0.000 & 0.000 & 0.000 & 0.000 \\
\hline \multicolumn{7}{|l|}{ Age, years } \\
\hline $40-50$ & 13.947 & $0.200^{* * *}$ & 49.246 & $3.953^{* * *}$ & 1.482 & $0.084^{* * *}$ \\
\hline $50-59$ & 11.427 & $0.360^{* * *}$ & 24.600 & $1.387^{* * *}$ & 3.336 & $0.204^{* * *}$ \\
\hline 60-64 (ref) & 0.000 & 0.000 & 0.000 & 0.000 & 0.000 & 0.000 \\
\hline \multicolumn{7}{|l|}{ Poverty status } \\
\hline Poor & -4.413 & $0.364^{* * *}$ & -26.722 & $2.274^{* * *}$ & 0.175 & $0.075^{*}$ \\
\hline Not poor (ref) & 0.000 & 0.000 & 0.000 & 0.000 & 0.000 & 0.000 \\
\hline \multicolumn{7}{|l|}{ Insurance } \\
\hline Medicare & -20.157 & $1.070^{* * *}$ & -65.879 & $2.041^{* * *}$ & -8.715 & $0.232^{* * *}$ \\
\hline Medicaid & -22.517 & $0.402^{* * *}$ & -97.583 & $3.419^{* * *}$ & -7.858 & $0.085^{* * *}$ \\
\hline Other & -3.039 & $0.233^{* * *}$ & -93.671 & $2.378^{* * *}$ & -3.626 & $0.092^{* * *}$ \\
\hline Uninsured & 29.976 & $0.716^{* * *}$ & -89.481 & $2.821^{* * *}$ & 16.327 & $0.310^{* * *}$ \\
\hline Private (ref) & 0.000 & 0.000 & 0.000 & 0.000 & 0.000 & 0.000 \\
\hline \multicolumn{7}{|l|}{ Region } \\
\hline Northeast & -0.760 & $0.180^{* * *}$ & 35.027 & $4.986^{* * *}$ & -2.035 & $0.107^{* * *}$ \\
\hline Midwest & 24.966 & $0.485^{* * *}$ & 26.265 & $2.896^{* * *}$ & 3.170 & $0.224^{* * *}$ \\
\hline South & 9.445 & $0.170^{* * *}$ & -30.213 & $1.916^{* * *}$ & 4.490 & $0.124^{* * *}$ \\
\hline West (ref) & 0.000 & 0.000 & 0.000 & 0.000 & 0.000 & 0.000 \\
\hline \multicolumn{7}{|l|}{ Mammogram site } \\
\hline Outpatient hospital & -10.571 & $0.396^{* * *}$ & 75.035 & $3.442^{* * *}$ & -6.112 & $0.212^{* * *}$ \\
\hline Office-based (ref) & 0.000 & 0.000 & 0.000 & 0.000 & 0.000 & 0.000 \\
\hline
\end{tabular}

Based on women aged 40-64, alive at the end of the year, received one mammogram in 2007 or in 2008. The regressions include intercept terms and are also controlled for other variables (the parameter estimates are not presented in this table): marital status, metropolitan status, education, employment, mental health, physical health, body mass index, smoking, clinical preventive care, number of chronic conditions, and calendar year of observation.

${ }^{\mathrm{a}}$ Out-of-pocket spending divided by total expenditures for mammogram and expressed in terms of percentages.

Asterisks represent significant differences compared to the reference group. ${ }^{* * *} p<0.0001 ;{ }^{* *} p<0.001 ;{ }^{*} p<0.01$.

ref, referent.

out-of-pocket mammography expenditures and total mammography expenditures and how these expenditures vary by insurance status and type, poverty status, facility where mammogram was received, and region of the United States where a woman resided at the time of the mammogram. Our study findings suggest that women without available resources that enable access to care, such as health insurance, had higher out-of-pocket mammography expenditures, which may pose a high financial burden. Such a financial burden is a potential barrier for receipt of mammograms in the future. Previous research by Trivedi et al. ${ }^{16}$ showed that a copayment as much as $\$ 10$ may deter eligible women from receiving a mammogram, and our study suggests that nationwide average out-of-pocket mammography expenditures are at least twice as high. Our findings also have implications for future screening decisions. ${ }^{16}$ High out-of-pocket mammography expenditures may negatively influence a woman's decision to receive future mammography screening. Study findings by McAlearney et al. ${ }^{6,10}$ highlighted how perceived cost or overestimation of cost of a mammogram can act as a barrier to receiving a mammogram.

Our study findings also confirm that even among women who received mammograms, the out-of-pocket mammography expenditures as a proportion of the total mammography expenditures varied by presence of insurance. These findings are consistent with those of another study, in which the authors reported that uninsured women were more likely to report paying some or all of the cost of their most recent mammogram compared to women who were insured. ${ }^{7}$ Further efforts are needed to identify available resources for these women in order to deflect their out-of-pocket mammography expenditures.

Additional variations in mammography expenditures were observed among women residing in different regions of the United States. Women in the Midwest bear nearly twice the out-of-pocket mammography expenditures as those who reside in the West. Women who reside in the Northeast have the lowest out-of-pocket mammography expenditures yet the highest total mammography expenditures of all regions. This may be explained by different reimbursement rates that are calculated based on the area's various labor market factors.

Other variations in mammography expenditures were observed between the types of facility where a mammogram was received. Compared to women who received mammograms at an office-based facility, women who received mammograms at a hospital outpatient facility had lower outof-pocket mammography expenditures but greater total mammography expenditures. Because of a shortage of 
specialists, many rural areas may not have an office-based facility that provides mammography services. Therefore, women may receive their mammogram at a hospital outpatient facility in either their area or some distance away.

Although adherence to recommended mammography screening guidelines was not the purpose of the present study, our sample (largely white, of high income, with private insurance) suggests that women for whom cost is not a barrier and out-of-pocket mammography expenditures do not present a high financial burden may be more likely to receive a mammogram. A descriptive comparison of women who did and who did not receive a mammogram in 2007 or 2008 is shown in the Appendix.

Major strengths of our study include large nationally representative data, comprehensive information on many variables that can be controlled for, and the availability of payments rather than charges for mammograms. However, some limitations need to be noted. A major limitation is that the study did not examine mammography expenditures associated with guideline-consistent mammography screening; the purpose of this study, however, was not to determine guideline-consistent mammography screening but how much the women were paying. Another limitation may arise from recall bias. To limit recall bias, the survey was conducted in five panels that occur in shorter intervals than if it was administered at one time. In addition, our sample may suffer from selection bias; for example, women classified as poor represented almost $15 \%$ of our sample, whereas they represented almost $36 \%$ of women 40-64 years of age who did not receive a mammogram during the calendar year. Furthermore, almost four times as many women $(20.8 \%)$ who were uninsured did not receive a mammogram during the calendar year compared to those who did (5.5\%). Finally, although this study only examined possible financial barriers to receiving a mammogram, nonfinancial barriers have been demonstrated to be equally effective at discouraging women from receiving a mammogram. Study findings from Schueler et al. ${ }^{43}$ found that women who did not have a usual source of care, did not see a obstetrician/ gynecologist, and did not have a physician recommend a mammogram were less likely to receive a mammogram. In addition, a lack of screening knowledge and particular mammography beliefs, as well as concerns about safety and pain, prevented receipt of mammography. ${ }^{43}$

Despite these limitations, our study estimated women's average out-of-pocket mammography expenditures. The average out-of-pocket mammography expenditure was found to be $\$ 33$. Although public insurance coverage reduced the average out-of-pocket mammography expenditures, the proportions of out-of-pocket mammography expenditures to total mammography expenditures were larger among some subgroups of women, suggesting that higher financial burden and higher cost sharing may influence women's decision to seek health services, especially those that are preventive, such as a mammogram. Further disparities in out-of-pocket mammography expenditures were seen among women who were uninsured and living in different geographic regions of United States and also in the type of facility where the mammogram was received.

Considering that the largest variations in out-of-pocket mammography expenditures were observed among uninsured women, the recently passed healthcare reform bill that includes provisions of the Patient Protection and Affordable
Care Act may be a step in the right direction to eliminate these disparities. (www.healthcare.gov/center/regulations/prevention/regs.html). ${ }^{44}$ This law prohibits the imposition of cost-sharing requirements with respect to evidence-based recommendations with a rating of A or B by the United States Preventive Services Task Force. Strict enforcement of this provision across regions and type of facilities that offer mammography screening will go a long way toward eliminating financial barriers to mammography screening.

\section{Acknowledgments}

T.L. (research) and U.S. (infrastructure) were partially supported by Collaborative Health Outcome Research of Therapies and Services (CoHORTS) grant 1 P20 HS 015 390-02.

\section{Disclosure Statement}

The authors have no conflicts of interest to report.

\section{References}

1. U.S. Preventive Services Task Force. Screening for breast cancer: U.S. Preventive Services Task Force recommendation statement. Ann Intern Med 2009;151:716-723.

2. American Cancer Society. How many women get breast cancer? Overview: breast cancer. Atlanta, GA: American Cancer Society, 2010. Available at www.cancer.org/Cancer/ BreastCancer/OverviewGuide/breast-cancer-overview-keystatistics Accessed September 7, 2010.

3. Nelson H, Tyne K, Naik A, Bougatos C, Chan B, Humphrey L. Screening for breast cancer: An update for the U.S. Preventive Task Force. Ann Intern Med 2009;151:727-737.

4. Berry D, Cronin K, Plevritis S, et. al. Effect of screening and adjuvant therapy on mortality from breast cancer. N Engl J Med 2005;353:1784-1792.

5. Humphrey L, Helfand M, Chan B, Woolf S. Breast cancer screening: A summary of the evidence for the U.S. Preventive Task Force. Ann Intern Med 2002;137:347-360.

6. McAlearney A, Reeves K, Tatum C, Paskett E. Cost as a barrier to screening mammography among underserved women. Ethnicity Health 2007;12:189-203.

7. Pagan J, Asch D, Brown C, Guerra C, Armstrong K. Lack of community insurance and mammography screening rates among insured and uninsured women. J Clin Oncol 2008; 26:1865-1870.

8. Calle E, Flanders D, Thun M, Martin L. Demographic predictors of mammography and Pap smear screening in US women. Am J Public Health 1993;83:53-60.

9. Data2010...The Healthy people 2010 database, January 2010 ed. Focus Area 03-Cancer. CDC wonder. Available at wonder.cdc.gov/data2010/focus.htm Accessed September 7, 2010.

10. McAlearney A, Reeves K, Tatum C, Paskett E. Perceptions of insurance coverage for screening mammography among women in need of screening. Cancer 2005;103:2473-2480.

11. Zapka J, Stoddard A, Costanza M, Greene H. Breast cancer screening by mammography: Utilization and associated factors. Am J Public Health 1989;79:1499-1502.

12. Breen N, Wagener D, Brown M, Davis W, Ballard-Barbash R. Progress in screening over a decade: Results of cancer screening from the 1987, 1992, and 1998 National Health Interview Surveys. J Natl Cancer Inst 2001;93:1704-1713.

13. American Cancer Society. Breast cancer facts and figures 2009-2010. Atlanta, GA: American Cancer Society, Inc. 
14. Rodriguez M, Ward L, Perez-Stable E. Breast and cervical cancer screening: Impact of health insurance status, ethnicity, and nativity of Latinas. Ann Fam Med 2005;3:235-241.

15. Solanki G, Schauffler H. Cost-sharing and the utilization of clinical preventive services. Am J Prev Med 1999;17:127-133.

16. Trivedi A, Rakowski W, Ayanian J. Effect of cost sharing on screening mammography in Medicare health plans. N Engl J Med 2008;358:375-383.

17. Solanki, G, Schauffler H, Miller L. The direct and indirect effects of cost-sharing on the use of preventive services. Health Serv Res 2000;34:1331-1350.

18. American Cancer Society. Cancer statistics 2009: A presentation from the American Cancer Society. Atlanta, GA: American Cancer Society, Inc.

19. Lohr K, Brook R, Kamberg G, Goldberg G, Leibowitz A. Use of medical care in the Rand Health Insurance Experiment: Diagnosis- and service-specific analysis in a randomized controlled trial. Med Care 1986;24:51-87.

20. Breen N, Brown M. The price of mammography in the United States: Data from the National Survey of Mammography Facilities. Milbank Q 1994;72:431-450.

21. Zhang P, Tao G, Irwin K. Utilization of preventive medical services in the United States: A comparison between rural and urban populations. J Rural Health 2000;16:349-356.

22. Nystrom L, Andersson I, Bjurstam N, Frisell J, Nordenskjold B, Rutqvist L. Long-term effects of mammography screening: Updated overview of the Swedish randomized trials. Lancet 2002;359:909-919.

23. Moss S, Cuckle H, Evans A, Johns L, Waller M, Bobrow L. Effect of mammography screening from age 40 years on breast cancer mortality at 10 years' follow-up: A randomized controlled trial. Lancet 2006;368:2053-2060.

24. Bjurstam N, Bjorneld L, Warwick J, et al. The Gothenburg breast screening trial. Cancer 2003;97:2387-2396.

25. Alexander F, Anderson T, Brown H, et al. 14 years of followup from the Edinburgh randomized trial of breast-cancer screening. Lancet 1999;353:1903-1908.

26. Kerlikowske K, Grady D, Rubin S, Sandrock C, Ernster V. Efficacy of screening mammography: A meta-analysis. JAMA 1995;273:149-154.

27. Sun J, Chapman J, Gordon R, Sivaramakrishna R, Link M, Fish E. Survival from primary breast cancer after routine clinical use of mammography. Breast 2002;8:199-208.

28. Somkin C, McPhee S, Nguyen T, et al. The effect of access and satisfaction on regular mammogram and Papanicolaou test screening in a multiethnic population. Med Care 2004; 42:914-926.

29. Scanlon W. Medicare hospital and physician payments: Geographic cost adjustments important to preserve beneficiary access to services. United States General Accounting Office. GAO-02-968T. Available at www.gao.gov/new .items/d02968t.pdf Accessed September 7, 2010.

30. Zapka J, Stoddard A, Maul L, Costanza M. Interval adherence to mammography screening guidelines. Med Care 1991;29:697-707.

31. Andersen R. Revisiting the behavioral model and access to medical care: Does it matter? J Health Soc Behav 1995;36:1-10.

32. Andersen R, Newman J. Societal and individual determinants of medical care utilization in the United States. Milbank Q 2005;83:1-28.

33. Galbraith A, Wong S, Kim S, Newacheck P. Out-of-pocket financial burden for low-income families with children: So- cioeconomic disparities and effects of insurance. Health Serv Res 2005;40:1722-1736.

34. Medical Expenditure Panel Survey. HC-113: 2007 Full year consolidated data file, November 2009. Agency for Healthcare Research and Quality, Rockville, MD. Available at www.meps.ahrq.gov/mepsweb/data_stats/download_ data/pufs/h113/h113doc.pdf Accessed September 7, 2010.

35. Medical Expenditure Panel Survey. Agency for Healthcare Research and Quality. Rockville, MD. Available at www.meps.ahrq.gov/mepsweb/ Accessed January 10, 2011.

36. Yu WW, Machlin S. Examination of skewed health expenditure data from the Medical Expenditure Panel Survey (MEPS). Agency for Healthcare Research and Quality Working paper No. 04002, October 2004. Available at www.ahrq.gov Accessed January 11, 2011.

37. Medical Expenditure Panel Survey. HC sample design and collection process. Agency for Healthcare Research and Quality, Rockville, MD. Available at www.meps.ahrq.gov/ survey_comp/hc_data_collection.jsp Accessed September 7, 2010.

38. Medical Expenditure Panel Survey. HC response rates by panel. Agency for Healthcare Research and Quality, Rockville, MD. Available at www.meps.ahrq.gov/mepsweb/ survey_comp/hc_response_rate.jsp Accessed January 3, 2011.

39. Methodology report 19. Overview of methodology for imputing missing expenditure data in the Medical Expenditure Panel Survey. Agency for Healthcare Research and Quality, Rockville, MD. Available at www.meps.ahrq.gov/mepsweb/ data_files/publications/mr19/mr19.pdf Accessed September 7, 2010.

40. Medical Expenditure Panel Survey. HC-121: 2008 Full year consolidated data file, November 2010. Agency for Healthcare Research and Quality, Rockville, MD. Available at www.meps.ahrq.gov/mepsweb/data_stats/download_data/ pufs/h121/h121doc.pdf Accessed January 3, 2011.

41. Machlin S, Cohen J, Beauregard K. Health care expenses for adults with chronic conditions, 2005. Statistical brief 203, 2008. Agency for Healthcare Research and Quality, Rockville, MD. Available at www.meps.ahrq.gov/mepsweb/ data_files/publications/st203/stat203.pdf

42. Consumer Price Index detailed report, tables annual average 2008. Washington, DC: Bureau of Labor Statistics. Available at www.bls.gov/cpi/cpid08av.pdf Accessed May 2, 2011.

43. Schueler K, Chu P, Smith-Bindman R. Factors associated with mammography utilization: A systematic quantitative review of the literature. J Womens Health 2008;17:14771498.

44. Interim Final Rules for Group Health Plans and Health Insurance Issuers Relating to Coverage of Preventive Services under the Patient Protection and Affordable Care Act. Available at www.healthcare.gov/center/regulations/prevention/ regs.html Accessed September 7, 2010.

Address correspondence to:

Traci LeMasters, M.A. School of Pharmacy

Department of Pharmaceutical Systems and Policy

West Virginia University Morgantown, WV 26506-9510

E-mail: tlemasters@hsc.wvu.edu 


\section{Appendix}

Comparison of Women Who Received One Mammogram and Those Without Any Mammogram: Medical Expenditure Panel Survey, 2007-2008

\begin{tabular}{|c|c|c|c|c|}
\hline \multirow[b]{2}{*}{ All } & \multicolumn{2}{|c|}{ Mammogram } & \multicolumn{2}{|c|}{ No Mammogram } \\
\hline & $\begin{array}{c}n \\
2020\end{array}$ & $\begin{array}{c}W t \% \\
23.7\end{array}$ & $\begin{array}{c}\mathrm{n} \\
7644\end{array}$ & $\begin{array}{c}W t \% \\
76.3\end{array}$ \\
\hline \multicolumn{5}{|l|}{ Race/ethnicity ${ }^{* * *}$} \\
\hline White & 1331 & 26.8 & 3751 & 73.2 \\
\hline African American & 262 & 15.7 & 1536 & 84.3 \\
\hline Latina & 290 & 15.6 & 1743 & 84.4 \\
\hline Other & 137 & 18.7 & 614 & 81.3 \\
\hline \multicolumn{5}{|l|}{$\mathrm{Age}^{* * *}$} \\
\hline $40-50$ & 756 & 19.9 & 3606 & 80.1 \\
\hline $50-59$ & 870 & 25.2 & 2967 & 74.8 \\
\hline $60-64$ & 394 & 30.2 & 1071 & 69.8 \\
\hline \multicolumn{5}{|l|}{ Poverty status ${ }^{* * *}$} \\
\hline Poor & 409 & 13.0 & 1196 & 87.0 \\
\hline Not poor & 1611 & 24.7 & 1536 & 75.3 \\
\hline \multicolumn{5}{|l|}{ Uninsured $^{* * *}$} \\
\hline Yes & 163 & 9.4 & 1590 & 90.6 \\
\hline No & 1857 & 26.0 & 6054 & 74.0 \\
\hline \multicolumn{5}{|l|}{ Medicare } \\
\hline Yes & 93 & 19.7 & 440 & 80.3 \\
\hline No & 1927 & 23.9 & 7204 & 76.1 \\
\hline \multicolumn{5}{|l|}{ Medicaid ${ }^{* * *}$} \\
\hline Yes & 152 & 14.6 & 1003 & 85.4 \\
\hline No & 1868 & 24.5 & 6641 & 75.5 \\
\hline \multicolumn{5}{|l|}{ Private insurance ${ }^{* * *}$} \\
\hline Yes & 1653 & 27.2 & 4876 & 72.8 \\
\hline No & 367 & 12.8 & 2768 & 87.2 \\
\hline \multicolumn{5}{|l|}{ TRICARE $^{* *}$} \\
\hline Yes & 62 & 35.2 & 132 & 64.8 \\
\hline No & 1958 & 23.5 & 7512 & 76.5 \\
\hline \multicolumn{5}{|l|}{ Perceived health***} \\
\hline Excellent/very good & 1164 & 27.5 & 3604 & 72.5 \\
\hline Good & 586 & 20.9 & 2526 & 79.1 \\
\hline Fair/poor & 270 & 15.9 & 1,514 & 84.1 \\
\hline \multicolumn{5}{|l|}{ Mental health ${ }^{* * *}$} \\
\hline Excellent/very good & 1343 & 25.8 & 4596 & 74.2 \\
\hline Good & 534 & 21.3 & 2259 & 78.7 \\
\hline Fair/poor & 143 & 15.8 & 789 & 84.2 \\
\hline \multicolumn{5}{|l|}{ Metro status } \\
\hline Metro & 1708 & 23.9 & 6424 & 76.1 \\
\hline Nonmetro & 312 & 22.8 & 1220 & 77.2 \\
\hline \multicolumn{5}{|l|}{ Region*** } \\
\hline Northeast & 347 & 25.1 & 1202 & 74.9 \\
\hline Midwest & 504 & 28.1 & 1392 & 71.9 \\
\hline South & 705 & 22.3 & 3021 & 77.7 \\
\hline West & 464 & 20.5 & 2029 & 79.5 \\
\hline \multicolumn{5}{|l|}{ Year } \\
\hline 2007 & 993 & 23.5 & 3767 & 76.5 \\
\hline 2008 & 1027 & 23.9 & 3877 & 76.1 \\
\hline
\end{tabular}

Based on women aged 40-64 years of age, alive at the end of the year who received one mammogram in 2007 or in 2008. Figures for women without mammogram need to be interpreted with caution because these do not represent women who did not receive guideline-consistent mammography screening.

Asterisks represent significant group differences based on chisquare tests.

TRICARE, a health care program offered by the Military Health System for active duty service members, National Guard and Reserve members, their families, survivors, and certain former spouses; Wt \%, weighted \%. 
